\title{
əTyphoon Type Index: A New Index for Understanding the Rain or Wind Characteristics of Typhoons and Its Application to Agricultural Losses and Crop Vulnerability
}

\author{
Yuan-Chien Lin, Wen-Hsin Wang, Chun-Yeh Lai, AND YONG-Qing Lin \\ Department of Civil Engineering, National Central University, Taoyuan, Taiwan
}

(Manuscript received 28 August 2019, in final form 10 March 2020)

\begin{abstract}
Heavy rainfall and strong wind are the two main sources of disasters that are caused by tropical cyclones (TCs), and typhoons with different characteristics may induce different agricultural losses. Traditionally, the classification of typhoon intensity has not considered the amount of rainfall. Here, we propose a novel approach to calculate the typhoon type index (TTI). A positive TTI represents a "wind type" typhoon, where the overall damage in a certain area from TCs is dominated by strong wind. On the other hand, a negative TTI represents a "rain type" typhoon, where the overall damage in a certain area from TCs is dominated by heavy rainfall. From the TTI, the vulnerability of crop losses from different types of typhoons can be compared and explored. For example, Typhoon Kalmaegi (2008) was classified as a rain-type typhoon (TTI $=-1.22)$. The most affected crops were oriental melons and leafy vegetables. On the contrary, Typhoon Soudelor (2015) was classified as a significant wind-type typhoon in most of Taiwan (TTI $=1.83$ ), and the damaged crops were mainly bananas, bamboo shoots, pomelos, and other crops that are easily blown off by strong winds. Through the method that is proposed in this study, we can understand the characteristics of each typhoon that deviate from the general situation and explore the damages that are mainly caused by strong winds or heavy rainfall at different locations. This approach can provide very useful information that is important for the disaster analysis of different agricultural products.
\end{abstract}

\section{Introduction}

Among the most serious natural disasters, tropical cyclones (TCs), typhoons, and hurricanes always bring heavy rainfall and strong wind, resulting in disasters such as flooding, mudflows, and landslides and causing severe damage to economies and casualties around the world. Heavy rainfall, strong wind, and storm surge are the three main sources of disasters that are caused by TCs. Among them, heavy rainfall from typhoons creates extreme rainfall events and causes several serious disasters, including floods, landslides, and mudslides. Furthermore, the increasing frequency and intensity of extreme rainfall events caused by climate change have been observed recently in Taiwan (Tu and Chou 2013) and worldwide (Ekström et al. 2005; Goswami et al. 2006; Yilmaz et al. 2014). Changes in precipitation amount, frequency, intensity, and duration (IPCC 2007)

Denotes content that is immediately available upon publication as open access.

Corresponding author: Yuan-Chien Lin, yclin@ncu.edu.tw may cause severe floods and droughts. For example, Typhoon Morakot, Typhoon Fanapi, and Typhoon Megi in 2009 and 2010 brought record-breaking rainfall intensity and amounts to different locations in Taiwan (Chien and Kuo 2011; Ge et al. 2010; Huanget al. 2014). In particular, Typhoon Morakot brought record-breaking rainfall in south Taiwan, causing approximately 700 deaths from mudslides during 7-9 August 2009.

In addition, heavy rainfall events from TCs induce serious damage to many crops that are vulnerable to flooding. On the other hand, strong wind from TCs can cause different types of damage, including destroying houses, buildings, telecommunications, and power lines and blowing away rice, wheat, and fruits (Blennow and Sallnäs 2004; Crane et al. 1994; Gardiner et al. 2016, 2008; Gresham et al. 1991; Shanmugasundaram and Reardon 1995). Some studies focused on disaster-loss assessment and quantitative risk management to determine the effects of typhoons on paddy and other crops, applying a fuzzy comprehensive evaluation method, fuzzy intelligent decision support system, and extreme value theory to assess losses and management from 
different natural hazards (Chen et al. 2011; Lai and Wu 2010; Wang et al. 2015; Zhou and Chan 2016). In terms of losses from flood damage, previous studies applied different flood models, including distributed hydrologic models and distributed flood loss-estimation models, to simulate hazards, for example, flood elevation or area (Dutta et al. 2003; Messner and Meyer 2006; Scawthorn et al. 2006). Geographic information systems (GIS) are also a useful tool to estimate losses from flood damage (Dutta and Herath 2001; Forte et al. 2006; Yang and Tsai 2000).

However, these studies did not focus on the actual agricultural losses but only provided a holistic assessment of the damage. Furthermore, a comprehensive analysis of agricultural losses from heavy rainfall in conjunction with strong wind from TCs is still lacking. One study was based on historical hurricane tracks, in conjunction with aggregated and disaggregated data, to econometrically evaluate the effect of hurricanes on agriculture in the Caribbean for the period 1961-2009 (Mohan 2017). The results illustrated that hurricanes have had a statistically significant negative effect on agriculture, with smaller islands being more negatively affected. This study also reported that 1) pooling disaggregated data across agricultural products may produce a more reasonably measured estimate of hurricane destruction than aggregated data levels; and 2) different agricultural products are affected differently by hurricanes, with substantial product heterogeneity demonstrated in terms of resilience to hurricanes. In other words, higher agricultural diversity in a region could increase resilience to typhoons.

Several studies have attempted to understand the different effects from different characteristics or parameters of tropical cyclones for the purpose of disaster mitigation and prevention. For example, studies showed that different typhoon trajectories can induce different spatial-temporal patterns of rainfall and wind speed in a watershed because of topographical effects, causing different disasters and runoff patterns (Huang et al. 2012; Lin et al. 2015, 2002; Wu et al. 2002; Yeh and Elsberry 1993a,b). Precisely predicting the rainfall and wind speed during TCs and understanding the movements of TCs, alongside other latent factors that affect extreme rainfall or strong winds from tropical cyclones, is important for water-resource management and typhoon disaster mitigation.

Several studies have proposed several methods to forecast long-term or short-term precipitation patterns or classify the characteristics of typhoons, including machine learning methods that use artificial neural networks (ANN) or support vector machines (SVM) (French et al. 1992; Kuligowski and Barros 1998; Lin and
Chen 2005; Lin and Wu 2009; Pan et al. 2011). In addition, ensemble meteorological models include perturbations in the initial conditions, data-analysis methods, and physical parameterizations to forecast typhoon rainfall (Hsiao et al. 2013). Climatology models that consider topographical lifting and variations in the rainfall rate with radius (Lee et al. 2006) and combined shear and topography (Lonfat et al. 2007) were developed to forecast typhoon rainfall. However, most of these studies predicted typhoon rainfall by using directly related weather or typhoon variables. These methods-that is, ANNs and SVMs-have difficulty determining the underlying interactions and nonlinear relationships between typhoons and local weather conditions.

Currently, the categories of typhoon intensity that are announced by the Central Weather Bureau (CWB) in Taiwan or other national weather services worldwide are all based only on wind speed and air pressure. For example, Taiwan's CWB classifies the categories of typhoons as intense, moderate, mild, and tropical depression based on the maximum wind speed near the center of TCs. In addition, the Dvorak technique (Dvorak 1984) is a widely used system to estimate tropical cyclone intensity around the world. However, this method also does not consider the potential maximum precipitation when distinguishing the intensity of typhoons. In other words, some typhoons bring extreme rainfall and cause major disasters such as mudflows and landslides but do not count as strong typhoons. Therefore, some problems will arise. For example, some typhoons have the same categories but different types of damage that is dominated by wind or rainfall. In fact, the characteristics of typhoons are quite different even when their tracks and intensities are similar. Moreover, disasters from typhoons will have considerable spatial heterogeneity because of the influence of spatial and terrain-based effects. Furthermore, a typhoon near Taiwan that interacts with southwesterly flow and northeasterly monsoons can affect the heavy rainfall pattern of the typhoon due to the topographical factors of Taiwan (Chen et al. 2013; Chien et al. 2008).

In other words, the intensity of rainfall and wind from TCs is not completely linearly related with a high correlation coefficient, especially when a TC center moves inland and rainfall can increase or decrease while winds decrease, and when a TC does not make landfall so the strongest winds are not experienced on land, but its outer rainbands can produce heavy rainfall. Although some severe typhoons have strong wind speeds and high pressure gradients, an insufficient amount of water vapor or fast-moving characteristics can cause the actual rainfall to be less than that of other typhoons with 
similar intensity categories-for example, Typhoon Soudelor (2015). On the other hand, some typhoons bring long-term heavy rainfall but no strong wind-for example, Typhoon Nari (2001). Therefore, from the perspective of disaster prevention, we should not define the intensity of typhoons only according to the wind speed and air pressure, and we should add the characteristics of rainfall to classify the different hazards that are induced by typhoons. According to several historical typhoon disaster reports in Taiwan, strong wind and heavy rainfall are the most typical factors that cause damage. Therefore, this study explores the characteristics of typhoons from the perspective of wind and rain.

In this study, we propose a novel approach to classify typhoon types based on historical observation datadriven techniques. A "rain type" typhoon occurs when the overall damage in a certain area is dominated by heavy rainfall. On the other hand, a "wind type" occurs when the overall damage in a certain area is dominated by strong wind. First, cumulative rainfall and wind speed datasets during each typhoon event from 1958 to 2016 were extracted, and spatial statistical regression models were built for all 32 weather stations countrywide. Then, the typhoon type index (TTI) was proposed and calculated for each historical typhoon and different space based on residual analysis. The importance of residuals during modeling is often overlooked. However, the meaning of the residual is actually very important. In scatterplots of linear models, we often want to see how close a scatter point is to the fitted line, but if we analyze the residual of a certain data point, a point that is farther from the fitted line is more representative for a certain axis. Thus, this approach could reveal the state of deviation for the data point to a certain variable. In this case, the higher the wind speed that is caused by the typhoon at a given weather station, the higher the rainfall. Therefore, we can fit a linear line for these two variables. Nevertheless, sometimes this scenario does not apply. The residual distance from the fitted line then becomes a desirable indicator for the quantitative classification of rain-type and wind-type typhoons, that is, the TTI that is proposed in this study. After the TTI is calculated spatially and temporally, the agricultural losses from each typhoon event are investigated alongside different TTIs to understand the characteristics and risks of different typhoon types for different crop hazards.

\section{Methods}

\section{a. Data}

Continuous spatial and temporal weather-observation data with various detailed meteorological information as observed by the CWB in Taiwan were obtained from the Data Bank for Atmospheric and Hydrologic Research and were archived by the Taiwan Typhoon and Flood Research Institute. Hourly meteorological data with time series from 1958 to 2016 were sliced and picked according to their warning periods as alerted by the CWB.

After capturing the weather data during typhoon periods, we selected rainfall and wind speed data from all the weather stations by each typhoon event to analyze the characteristics of each historical typhoon in Taiwan. The cumulative precipitation during each typhoon period can represent the rain intensity. Moreover, the mean value of the top $25 \%$ wind speed represents the strength of the strong wind that is caused by the typhoon. Some values in these meteorological data are notable. We applied some simple interpolation techniques, including linear interpolation, to fill in data that were absent because of sensor shutdown or failure. In addition, "rain trace" indicates data where the precipitation was less than $0.5 \mathrm{~mm}$, which we defined as zero.

Information regarding agricultural losses from disaster damage in Taiwan was obtained from the Council of Agriculture, Executive Yuan. These data contain the various crop losses from different natural disasters that occur each year, including "damaged areas," "percentage damaged," and "actual damaged areas." We select percentage damaged as our major target. The percentage damaged refers to the degree of damage inflicted by agricultural disasters on crops, which is the percentage reduction in harvest. We captured typhoon data for the risk analysis of agricultural damage based on the spacetime classification of each typhoon's characteristics.

\section{b. Statistical regression model and TTI}

Several statistical regression models for each weather station were built to classify the numerous typhoons into two types: wind type and rain type. Wind type indicates that the overall damage in a certain area was dominated by strong wind. On the other hand, rain type indicates that the overall damage in a certain area was dominated by heavy rainfall. The typhoon classification method in this study was based on residual analysis from fitting basic linear regression models at all weather stations countrywide:

$E\left(Y \mid X_{1}, X_{2}, \ldots, X_{p}\right)=a+\beta_{1} X_{1}+\beta_{2} X_{2}+\cdots+\beta_{p} X_{p}$,

where $Y$ is the response variable, that is, wind speed, and $X_{i}$ are independent variables, that is, cumulative rainfall, with coefficients $\beta_{i}$ and a constant intercept $\alpha$.

To assess the performance of the fitted line, residuals were used as a quantitative assessment based on the 
vertical deviations from the regression line. Consider one independent variable $x$ and dependent variable $y$ with $n$ data points. The height of the regression line above the $i$ th data point $\left(x_{i}, y_{i}\right)$ is

$$
\widehat{y}_{i}=\alpha+\beta x_{i}, \text { for } i=1,2, \ldots, n .
$$

The residual is defined as

$$
\text { Resid }=y_{i}-\widehat{y}_{i}=y_{i}-\left(\alpha+\beta x_{i}\right), \text { for } i=1,2, \ldots, n \text {. }
$$

A residual is positive if the corresponding point in the scatterplot lies above the regression line and negative if the point lies below the line. We set the cumulative rainfall and mean value of the top $25 \%$ wind speed during each typhoon as the $x$ axis and $y$ axis in a scatter diagram (Fig. 1) according to the data for each weather station near each typhoon in Taiwan. Generally, the cumulative rainfall of typhoons has a positive correlation with wind speed. Therefore, a typhoon event on (or near) the regression line represents a "normal" phenomenon. However, if the event is far from the regression line, that is, the absolute residual is large, the typhoon represents a special situation that is biased toward a certain characteristic. For example, if the residual is positive, the characteristics of the typhoon event are biased toward the characteristics that are represented by the $y$-axis variable; if the residual is negative, the characteristic is biased toward the $x$ axis, that is, a strong wind typhoon or heavy rainfall typhoon.

In the diagram, each point represents a typhoon event, each of which can be classified into two types based on the fitted line of the regression model, which was defined as the category line. The typhoons above the category line are defined as wind-type events, and those below are defined as rain-type events. After classifying these typhoons, the degree of their features can also be observed. The relationship between each typhoon point and the regression line on the scatter diagram enables more precise descriptions of the typhoons. The residuals of each point reveal the state of deviation for the data point to a certain variable. The residual distance from the fitted line then becomes a desirable indicator for the quantitative classification of rain-type and wind-type typhoons, that is, the TTI, which provides quantitative indicators for each typhoon type. Furthermore, windtype typhoons indicate that wind features were more obvious than rain in this area, while rain-type events show that rainfall hazards were relatively more significant than wind. In other words, we can rewrite Eq. (3) and define the TTI for each typhoon event $i$ and each weather station $j$ as

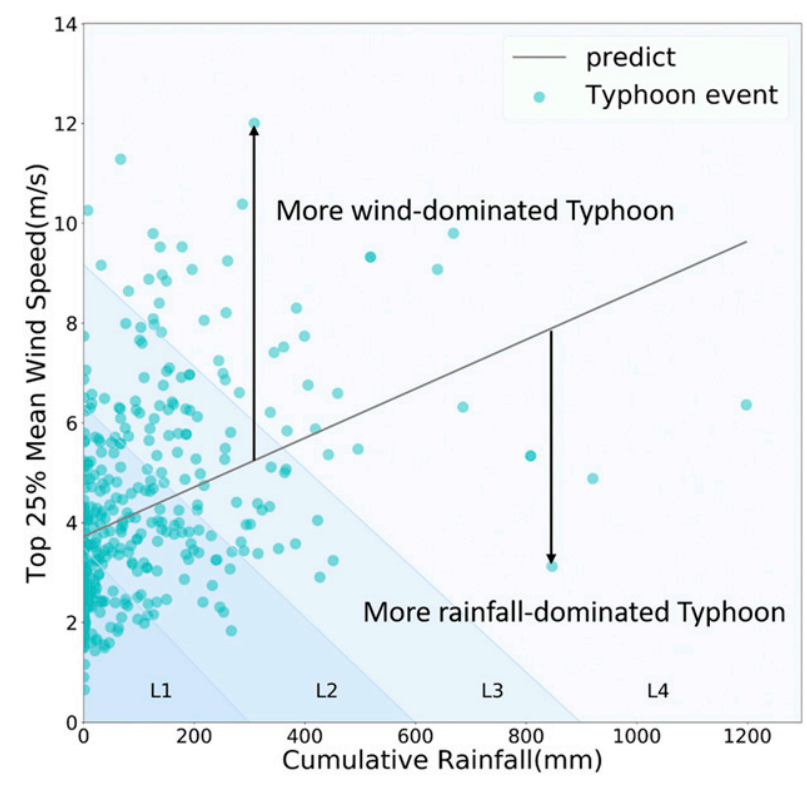

FIG. 1. Typhoon classification model for the Tawu weather station (CWB station 467540). The $x$-axis value is the cumulative rainfall $(\mathrm{mm})$, and the $y$-axis value is the top $25 \%$ of the mean wind speed $\left(\mathrm{m} \mathrm{s}^{-1}\right)$ for every typhoon. Points above the category line are more wind-dominated typhoons, and those below the line are more rain-dominated typhoons; L1-L4 are the boundaries of different levels represent different combined impacts of wind and rain intensity of typhoons.

$$
\begin{aligned}
\mathrm{TTI}_{i j} & =y_{i j}-\widehat{y}_{i j}=y_{i j}-\left(\alpha_{j}+\beta_{j} x_{i j}\right), \quad \text { for } \\
i & =1,2, \ldots, n, \quad j=1,2, \ldots, m,
\end{aligned}
$$

where $x_{i j}$ is the cumulative rainfall $(\mathrm{mm})$ during the warning period for each typhoon event $i$ and each weather station $j, y_{i j}$ is the top $25 \%$ of the mean wind speed $\left(\mathrm{m} \mathrm{s}^{-1}\right)$ for each typhoon event $i$ and each weather station $j, \widehat{y_{i j}}$ is the fitted value on the regression line that corresponds to $x_{i j}, \alpha_{j}$ and $\beta_{j}$ are parameters for weather station $j, n$ is the number of typhoon events, and $m$ is the number of weather stations, with $m$ regression models built. We used the Python programming language to develop programs to implement TTI calculations.

TTI can be combined with the typhoon intensity information for two dimensions comprehensive evaluation. For example, the meaning of TTI under strong typhoons and TTI under mild typhoons may be different, but TTI can independently understand the degree of typhoon deviation from wind or rain under various intensities. In Fig. 1, we also classify four levels (L1-L4), which represent the intensity of wind and rain impact of different typhoons. We can calculate the TTI value and check what level it falls in. In other words, L1-L4 can be regarded as the boundaries of different levels representing the different combined impacts of wind and rain 

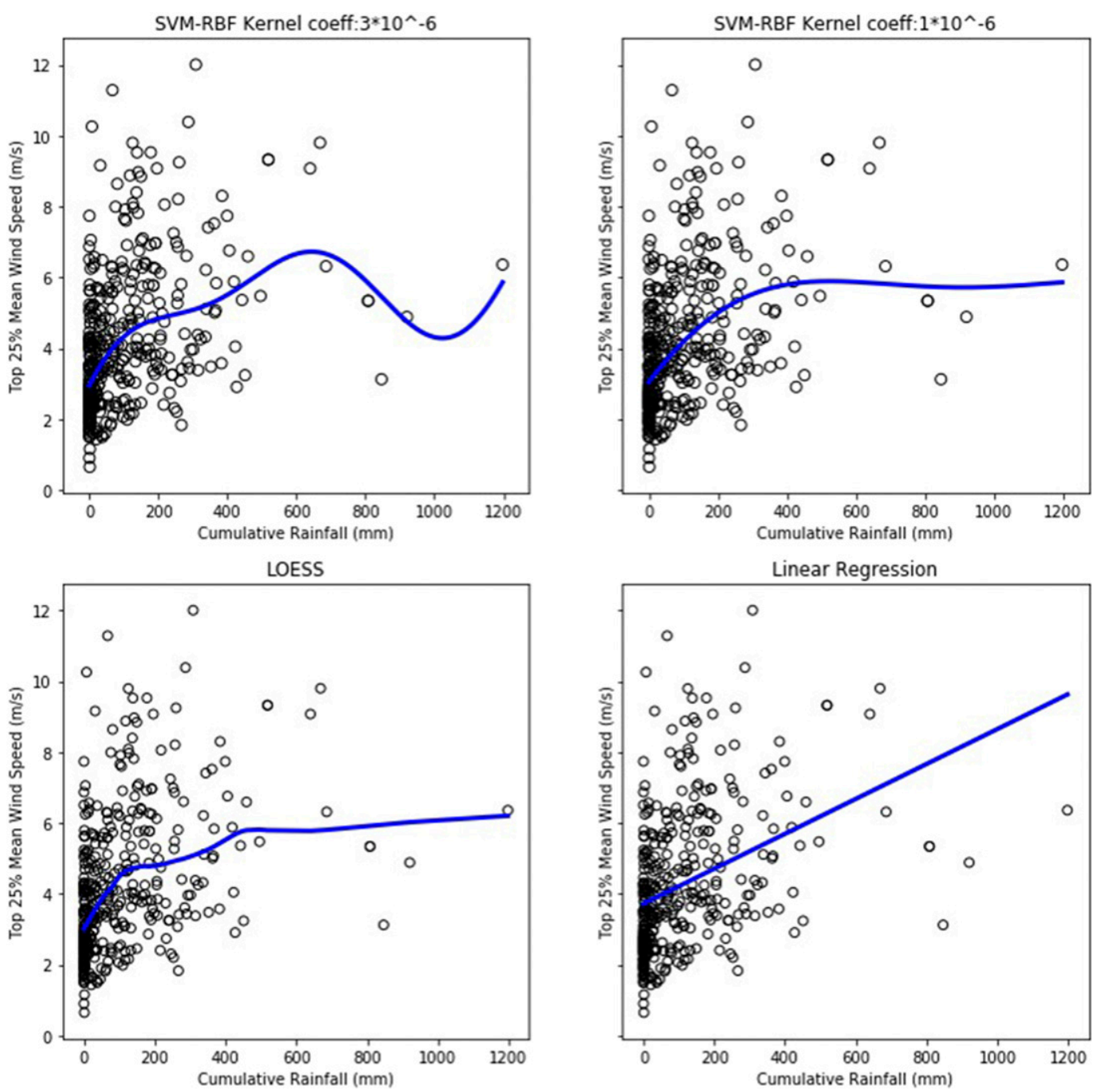

FIG. 2. Comparison of different linear or nonlinear models (SVM-RBF model with a kernel coefficient of $3 \times 10^{-6}$, SVM-RBF model with a kernel coefficient of $1 \times 10^{-6}$, LOESS, and linear regression) for typhoon classification at the Tawu weather station (CWB station number 467540). The $x$-axis value is the cumulative rainfall $(\mathrm{mm})$, and the $y$-axis value is the top $25 \%$ of the mean wind speed $\left(\mathrm{m} \mathrm{s}^{-1}\right)$ for every typhoon.

intensity of typhoons based on the quantiles of the $x$ axis and $y$ axis.

On the other hand, to compare the availability of other nonlinear models to develop our framework, Fig. 2 shows a comparison of different linear and nonlinear models, including the SVM-radial basis function (RBF) model with a kernel coefficient of $3 \times 10^{-6}$, the SVMRBF model with a kernel coefficient of $1 \times 10^{-6}$, a locally estimated scatterplot smoothing (LOESS) model, and a linear regression model. The SVM-RBF model is an SVM model that is based on the kernel of an RBF, which is a machine-learning technique (Chang and Lin 2011; Keerthi and Lin 2003; Vapnik 1998). LOESS or locally weighted scatterplot smoothing (LOWESS) is also a nonlinear smoothing method. LOESS combines much of the simplicity of linear least squares regression with the flexibility of nonlinear regression. These methods can find the curve of nonlinear relationships between data points.

However, these nonlinear models in Fig. 2, especially the nonparametric models, could not fit the relationship between the rainfall and wind speed. Different methods or parameters had completely different classification results, as shown in Fig. 2. The curves were also very sensitive to extreme values and the kernel coefficients for the SVM-RBF models, facilitating overfitting. On the other hand, the overall relationship was scattered but linear, and the model should be applicable to all stations. The objective of our framework is not to produce accurate predictions but to classify the characteristics. 
Therefore, a parametric linear model is the best choice for classifying typhoon types.

\section{Results}

a. $T T I$

The distance from each typhoon point to the fitted regression line along the direction of the $y$ axis is the residual of the regression model (Fig. 3) for each weather station. Furthermore, the value of the residual indicates how much this typhoon tended to be a winddominated type or rain-dominated type event. A positive residual represents a wind-dominated typhoon, which is above the regression line on the diagram. In contrast, a negative value represents a rain-dominated typhoon. By adding a vertical line at the median of Fig. 3 along the $x$ axis, weak wind and rain, strong wind and rain, strong wind and weak rain, and strong rain and weak wind can be also separated.

Every typhoon can obtain a residual value that is representative of wind and rain characteristics, so we defined the residual as the TTI (Fig. 4). The TTI is a value around zero. For each typhoon event, we can calculate the TTI at each weather station. In addition, a larger TTI value (positive) indicates stronger wind hazards for this typhoon event in the area near the weather station, while a smaller TTI value (negative) indicates stronger rainfall hazards for this typhoon event in the area near the weather station. If a TTI value is near zero, the typhoon event at this station has a generally average pattern without significant characteristics of rainfall or wind hazards. Therefore, the TTI can provide useful information for the analysis of typhoon features. Moreover, the size of the absolute value of the TTI shows the intensity of the feature. This index enables us to more precisely and explicitly recognize the characteristics of a typhoon.

Figure 3 shows some representative stations to illustrate the TTI-analysis framework. According to the fitted line, a positive correlation exists between the cumulative rainfall and top $25 \%$ mean wind speed for all weather stations. However, the slope and linear relationships for different weather stations are different because of the fixed spatial location patterns and terrain effects. Therefore, the classification procedure is based on each weather station. Strong wind from typhoons has a linear relationship with rainfall but does not completely follow the regression line and instead is scattered around the regression line. Figure 3 verifies our initial hypothesis that not all super typhoons have extreme rainfall. On the other hand, several typhoons also had low wind speed but extremely high cumulative rainfall. For example, the scatterplot for the Tawu weather station (CWB station 467540$)$ showed that a considerable number of typhoons had a high top $25 \%$ mean wind speed ( $y$ axis) but low cumulative rainfall ( $x$ axis), even sometimes less than $200 \mathrm{~mm}$. Such points were marked in red (wind type). On the contrary, the blue points (rain type) had considerably larger cumulative rainfall, sometimes even larger than $800 \mathrm{~mm}$, but their corresponding $25 \%$ wind speed was very small $\left(\leq 6 \mathrm{~m} \mathrm{~s}^{-1}\right)$. Therefore, we could quantify these points through the TTI.

We then extended this TTI method to all the CWB weather stations in Taiwan for every typhoon event officially warned by CWB. Figure 4 shows the overall average TTI at every weather station of 96 recent typhoons near Taiwan from 2001 to 2016 . Typhoons with a positive TTI were wind-type events (red bars), while negative values represented rain-type typhoons (blue bars). Even without spatial information, this approach revealed the typical hazard effects from different typhoons. The overall TTI variation showed that rain-type typhoons occurred much more often than wind-type typhoons in Taiwan from 2001 to 2016. In addition, the frequency of larger negative and positive TTIs appeared to be potentially cyclical. That is, the rain-type typhoons and wind-type typhoons usually take turns during a period of time, and especially rain-type typhoons often have a chance of continuous occurrence.

Table 1 lists the overall average TTI values and their corresponding typhoon types for some representative typhoons near Taiwan from Fig. 4 based on the TTI classification technique that was proposed in this study. For example, Typhoon Nari (2001) was a strong raintype event with a TTI of -2.7 ; on the other hand, Typhoon Soudelor (2015) was a strong wind-type event with a TTI of 1.83 . For these two typhoon events, the TTI-analysis results did provide very useful information regarding the different types of typhoons. Furthermore, the general damage types corresponded with the TTI values when these typhoons hit Taiwan.

\section{b. Spatial distribution of the TTI}

Meteorological data from a total of $32 \mathrm{CWB}$ weather stations in Taiwan were used in this research. The same typhoon may develop various wind-rain characteristics in different areas, so a typhoon could produce different TTIs at every weather station because of the typhoon's track and the effects of the location and terrain near the station. Therefore, we marked the TTI for each station on a map of Taiwan with different colors and performed spatial estimation to obtain the spatial distribution of the TTIs for each typhoon event (Fig. 5). The spatial distribution shows the geographical allocation of the wind and rain characteristics from a particular typhoon, 

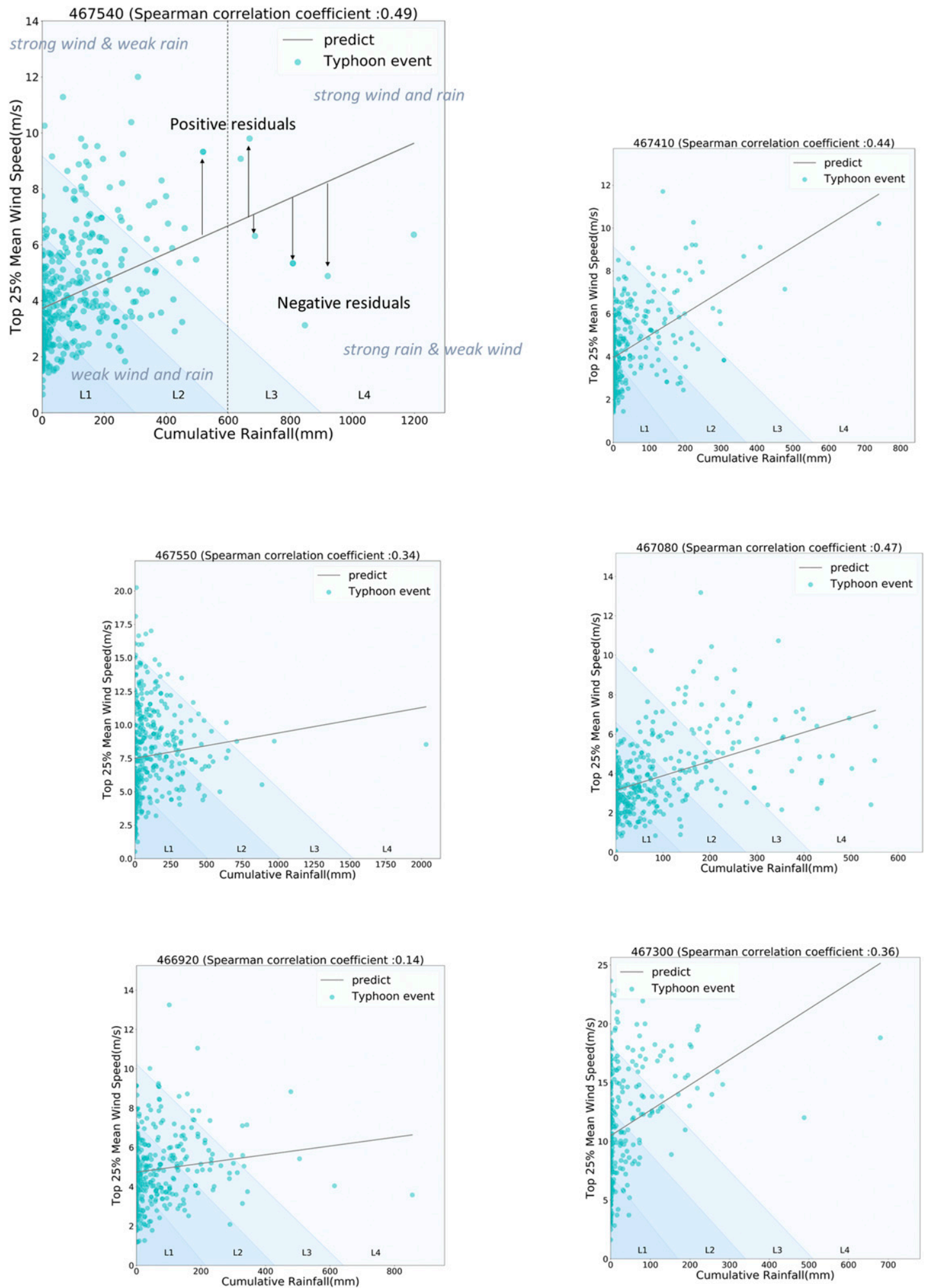

FIG. 3. Classification of different types of typhoons for each weather station. The residual of the regression model, which is the distance from each typhoon point to the regression line along the direction of the $y$ axis, indicates the degree of wind or rain features for a typhoon [CWB station 467540 (Tawu) $r=0.49,467410$ (Tainan) $r=0.44,467550$ (Yushan) $r=0.34,467080$ (Ilan) $r=0.47,466920$ (Taipei) $r=0.14$, and 467300 (Tungchitao) $r=0.36$ ]. 


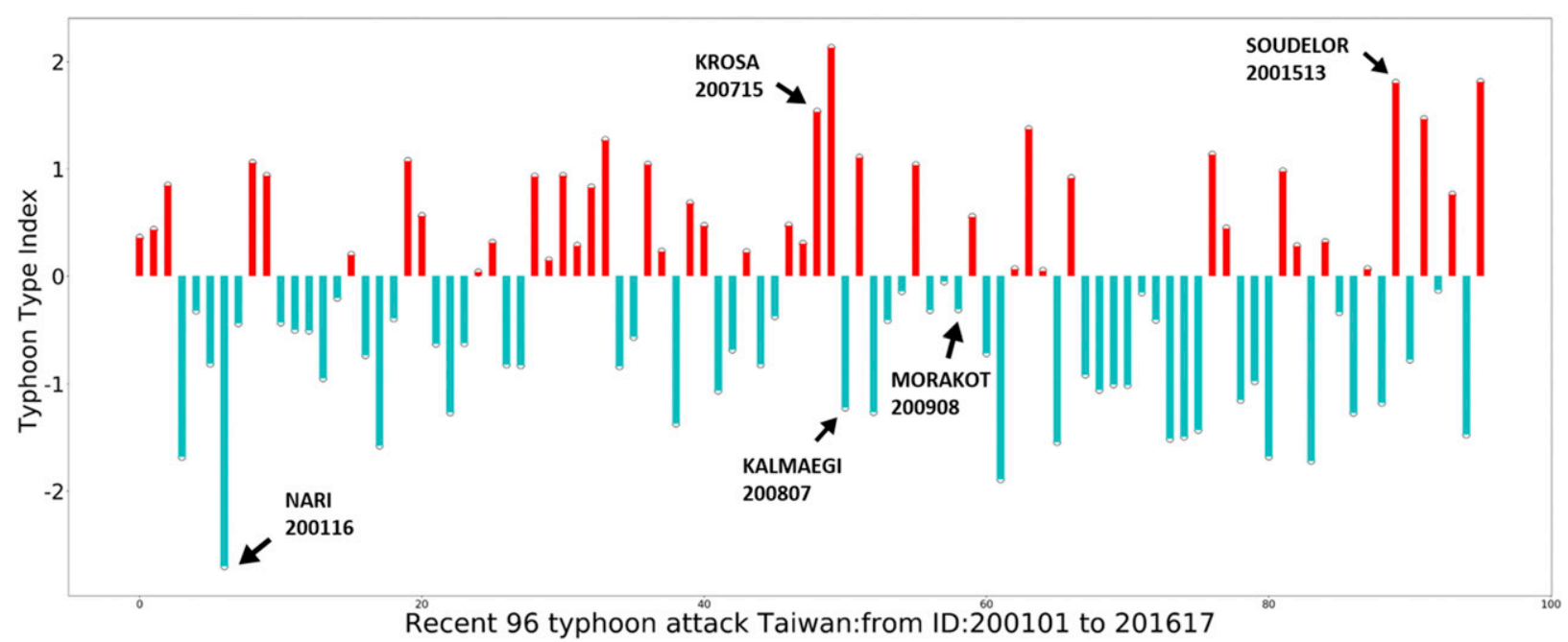

FIG. 4. Average TTI of 96 recent typhoons near Taiwan. Typhoons with a positive TTI are more wind-dominated typhoons, and negative values represent more rain-dominated typhoons.

which can be quite different because of terrain effects (Fig. 5c). We can clearly recognize wind or rain features from the color, which represents the TTI value, on the spatial distribution map. Wind-affected areas are displayed in red, indicating that strong wind was more obvious than rain in this area for this typhoon event. For example, Fig. 5a shows that Typhoon Krosa (2007) was a strong wind-type event throughout the study area, especially the middle of Taiwan. Similarly, Typhoon Gloria (1963) and Typhoon Soudelor (2015) were both strong wind-type events that are shown in Figs. $5 \mathrm{f}$ and $5 \mathrm{~h}$, respectively. For Typhoon Gloria (1963), the wind pattern in the northern region was more significant, while Typhoon Soudelor (2015) was a particularly strong windtype event in the northeast and northwest. On the other hand, rain-type areas are represented in blue, showing that heavy rainfall was relatively more significant than strong wind in this area. For example, Typhoons Nari (2001), Wayne (1986), and Kalmaegi (2008) are shown in Figs. 5b, 4e, and $4 \mathrm{~g}$, respectively. The track of Typhoon Xangsane (2000) traveled from south to north across Taiwan, resulting in a special TTI spatial distribution in which the entirety of western Taiwan was hit by strong winds, while the east and north were mainly dominated by heavy rainfall (Fig. 5c). Typhoon Herb (1996) (Fig. 5d) was one of the most severe typhoons to have ever hit Taiwan. This event brought strong winds to the plains, while the mountains were mainly dominated by heavy rainfall. In general, there are spatial patterns to the index: those closer to the coastline have a better chance of wind type (e.g., Figs. 5a,c,d,f,h).

A typhoon event may cause strong winds in the northeastern region but heavy rainfall in the southwest.
The most well-known and concrete example is Typhoon Morakot (2009) (average TTI $=-0.73$ ). The TTI spatial distribution of Morakot (Fig. 6) illustrates that most areas of Taiwan had a negative TTI, shown in blue on the map. More specifically, Morakot brought heavy precipitation in Taiwan, and strong wind was not obvious compared to rainfall. However, the southeastern island of Lanyu was marked with a positive TTI, showing that Lanyu experienced significantly strong gales even though Taiwan was hit by torrential rain. To compare with the actual disaster situation, the Typhoon Investigation Report of Morakot from the Central Weather Bureau indicated that Morakot caused record-breaking rainfall in the central, southern, and southeastern regions of Taiwan. During the event, the observed rainfall in 10 counties exceeded $1000 \mathrm{~mm}$.

TABLE 1. TTI values and corresponding typhoon types from some representative typhoons in the vicinity of Taiwan based on the TTI classification technique proposed in this study. Here, ID is identifier.

\begin{tabular}{clcl}
\hline \hline Typhoon ID & Name & TTI & \multicolumn{1}{c}{ Type } \\
\hline 201614 & Meranti & 0.76 & Wind type \\
201601 & Nepartak & -0.2 & Rain type \\
201513 & Soudelor & 1.83 & Wind type \\
201307 & Soulik & 0.45 & Wind type \\
200908 & Morakot & -0.73 & Rain type \\
200807 & Kalmaegi & -1.22 & Rain type \\
200715 & Krosa & 1.53 & Wind type \\
200306 & Soudelor & -0.2 & Rain type \\
200116 & Nari & -2.7 & Rain type \\
200020 & Xangsane & 1.21 & Wind type \\
199608 & Herb & 0.78 & Wind type \\
\hline
\end{tabular}




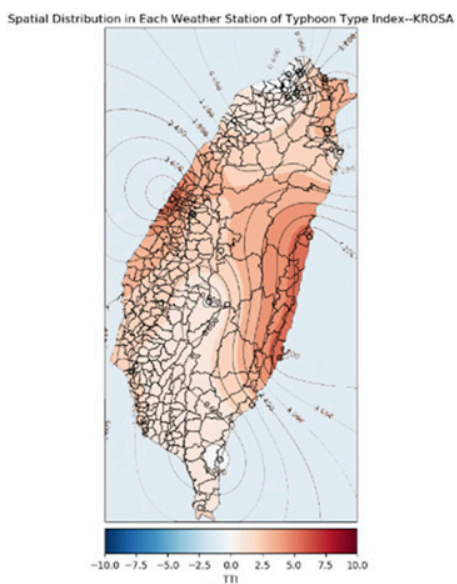

(a)

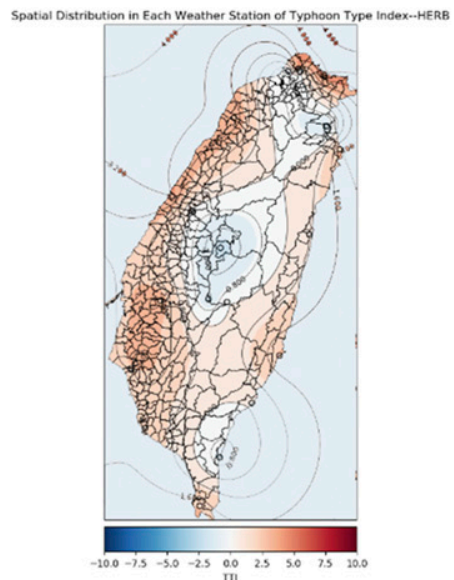

(d)

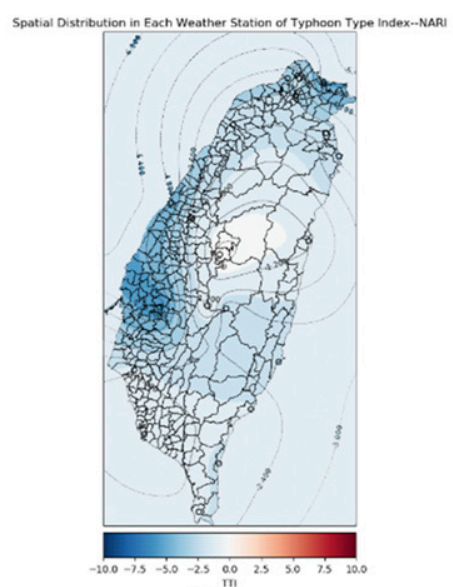

(b)

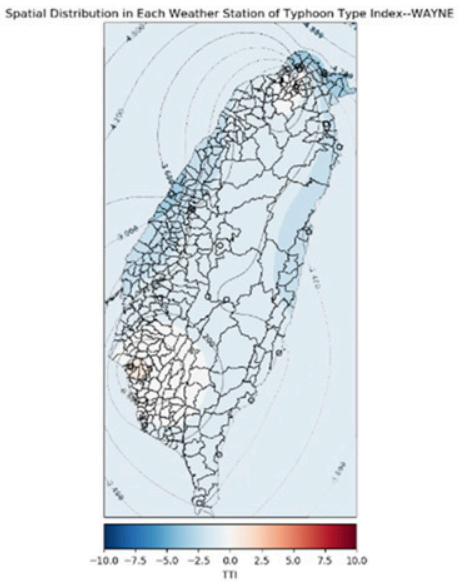

(e)

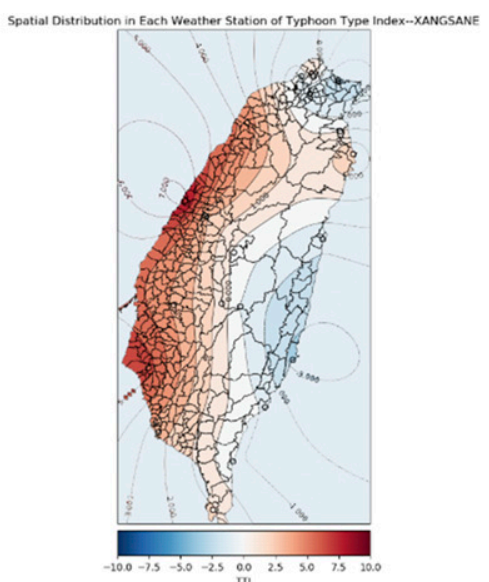

(c)

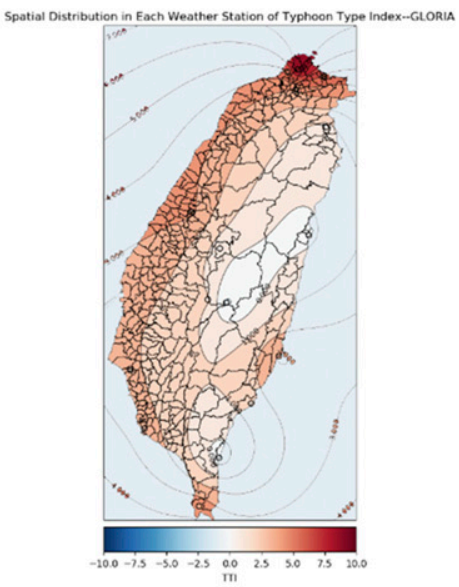

(f)

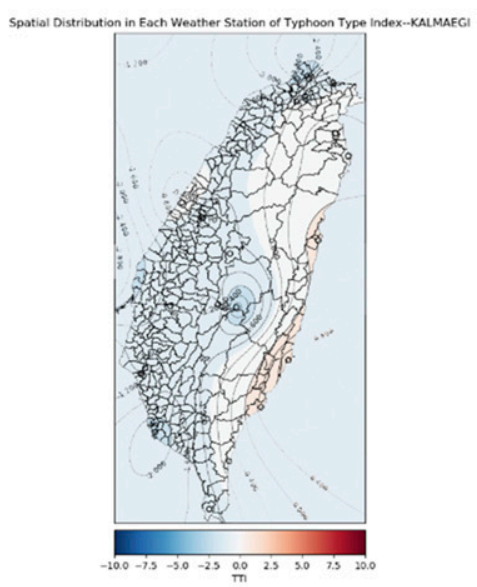

(g)

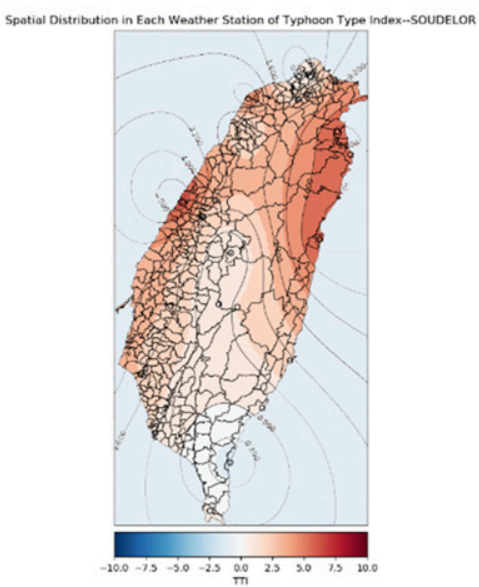

(h)

FIG. 5. Spatial distribution of the TTIs over Taiwan. This distribution map includes some famous typhoons that caused severe disasters: (a) Krosa, (b) Nari, (c) Xangsane, (d) Herb, (e) Wayne, (f) Gloria, (g) Kalmaegi, and (h) Soudelor. The red color represents a wind-type TTI distribution, and the blue color represents a rain-type distribution. According to the spatial distribution, Typhoon Kalmaegi was a prominent rain-type typhoon, with a large blue area on the map. On the contrary, Soudelor was an obvious wind-type typhoon in most of Taiwan, as indicated by the red color. 


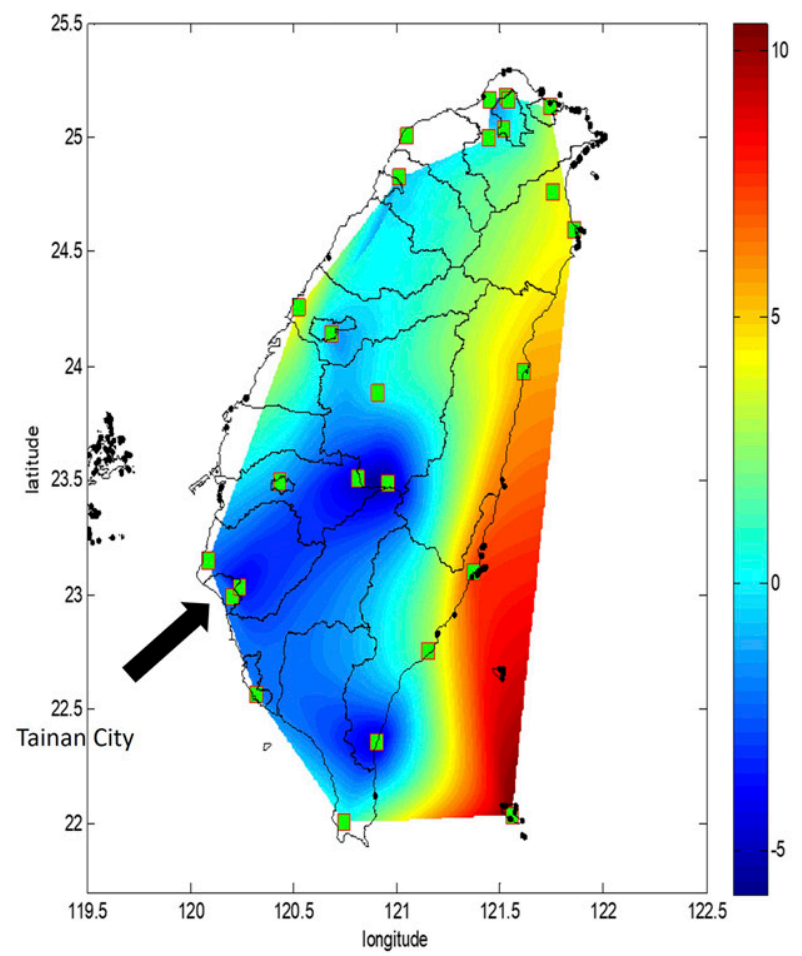

FIG. 6. TTI spatial distribution of Morakot, illustrating that most areas of Taiwan had a negative TTI (rainfall dominated), as indicated by blue on the map. However, the southeastern island of Lanyu was marked with a positive TTI (wind dominated), showing that when torrential rain hit the main island of Taiwan, Lanyu experienced significantly strong gales instead.

The cumulative rainfall of the three most affected areas, namely, Chiayi, Pingtung, and Kaohsiung Counties, exceeded $2500 \mathrm{~mm}$. This rainfall distribution was very consistent with the TTI's spatial distribution (Fig. 6). Therefore, this TTI spatial distribution map revealed that the characteristics of typhoons are regional, that is, different regions can have different wind and rain characteristics for the same typhoon.

\section{c. Application case: Agricultural-loss analysis}

Different types of crops have diverse resistance to different characteristics of natural disasters. Leafy crops and melon crops usually experience the most serious damage during heavy rain. On the other hand, crops such as pomelos and bananas are fragile and vulnerable to strong winds because the fruit or branches are easily blown off. Based on the historical TTI information in this study, we can further analyze crop-loss data from the Council of Agriculture and explore the relationship between the TTI and corresponding agricultural losses.

Typhoon Soudelor (2015) was classified as one of the most significant wind-type typhoons by the TTI (TTI = 1.83 on average). Moreover, the statistical data of crop losses indicated that among the total agricultural loss from Soudelor, the top five damaged crops were bananas, bamboo shoots, pomelos, guavas, and papayas, which made up $18 \%, 9 \%, 7 \%, 6 \%$, and $6 \%$, respectively (Fig. 7a). The circumstances tended to involve crops being blown off by strong wind, matching the features of wind-type typhoons.

Another significant case was the agricultural losses from Typhoon Kalmaegi (2008), which was classified as a rain-type typhoon in this study (TTI $=-1.22$ on average.). Although the Central Weather Bureau defined Kalmaegi as a mild typhoon, this event brought considerable rainfall and caused serious disasters in Taiwan. The most damaged crop from Kalmaegi, which made up $12 \%$ of the total loss of value, was oriental melons, which grow on the ground and are therefore vulnerable to flooding. In addition, the other most important crop loss, which also made up $12 \%$ of the total loss of value, was leafy vegetables. Leafy vegetables that grow on the ground are also very vulnerable to heavy rainfall damage, as their roots and leaves are easily damaged during flooding (Fig. 7b).

As mentioned above, the same typhoon can exhibit various TTIs at different positions. Thus, the crop-loss conditions can vary in different locations during the same typhoon. Analyzing the crop-loss circumstances in a certain region from the TTI spatial distribution could be more precise than when using the average TTI. Here, we focused on the agricultural loss in Tainan, which is the major agricultural area in Taiwan and in which crop species and amounts are relatively abundant.

The TTI of Soudelor in the Tainan area was 1.97, showing that wind characteristics were more prominent than the average value for Taiwan $(\mathrm{TTI}=1.8)($ Table 2$)$. The loss conditions of wind-vulnerable crops (the top five damaged crops were Wendan pomelos: $36.85 \%$, papayas: $10.87 \%$, longans $10.17 \%$, bamboo shoots: $9.28 \%$, and bananas: $5.08 \%$ ) were significantly more obvious than those for all of Taiwan (Fig. 8a). All these major damaged crops are more susceptible to strong winds. This result was consistent with the TTI spatial distribution, so the TTI shows a good ability to identify wind-damage or raindamage typhoon types.

Another case in Tainan was the crop-loss conditions during Typhoon Kalmaegi (2008), whose TTI in the Tainan area was -1.08 (average in Taiwan $=-1.22$ ). The precipitation effects of this typhoon were relatively milder in Tainan than those in the entire country. The loss tendencies of rain-vulnerable crops in Tainan (muskmelons: $24.43 \%$, papayas: $22.61 \%$, mangos: $9.14 \%$, and watermelons: $8.57 \%$ ) were not obvious compared to those for the entire region (Fig. 8b). Compared to the total crop-loss ratio in Taiwan, which were mostly oriental melons and 
TYPHOON SOUDELOR (2015) -BY VALUE LOSS

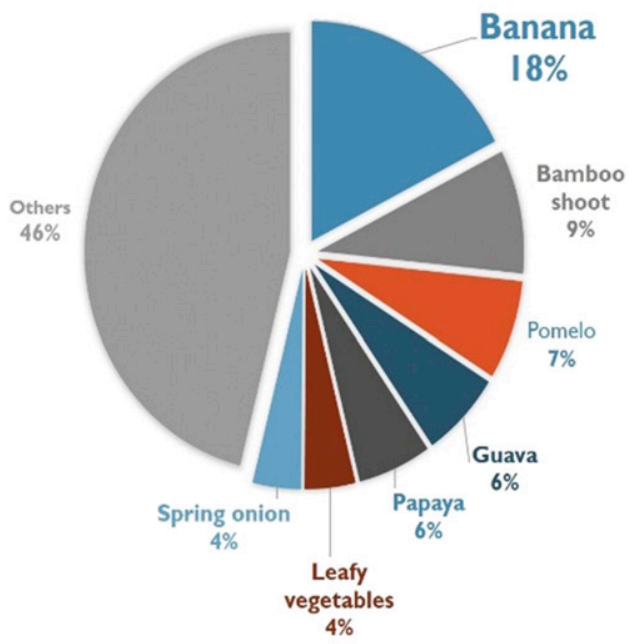

(a) SOUDELOR

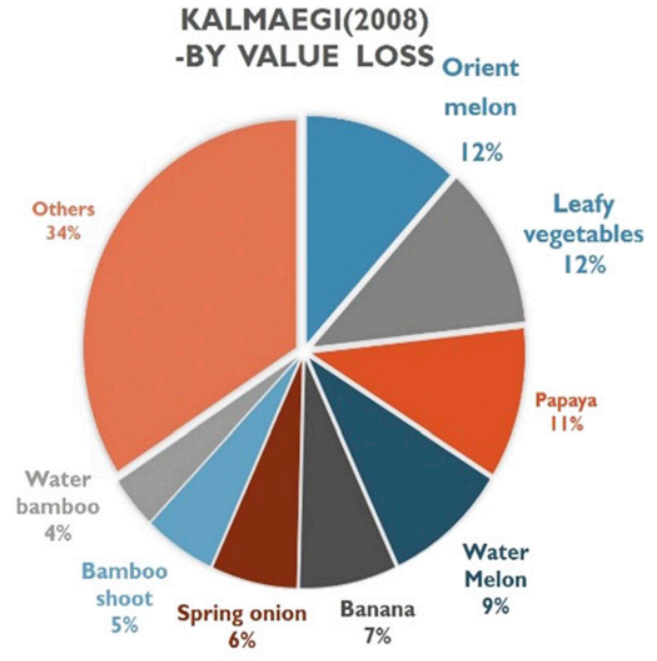

(b) KALMAEGI

FIG. 7. Pie chart of crop losses: (a) Soudelor, where the top five damaged crops were bananas, bamboo shoots, pomelos, guavas, and papayas $(18 \%, 9 \%, 7 \%, 6 \%$, and $6 \%$, respectively). All of these crops were easily blown off by strong winds. (b) Kalmaegi, where the most damaged crops, making up $12 \%$ each of the total loss, were oriental melons and leafy vegetables, which grow on the ground and are therefore vulnerable to flooding.

leafy vegetables, the TTI revealed local typhoon-type information and corresponding crop damage. This result was consistent with the TTI spatial distribution.

\section{d. Crop vulnerability}

To determine the crop-loss trend alongside the TTI for each crop, we drew scatterplots, which set the TTI values and crop-loss values during every typhoon event from 2003 to 2016 as the $x$ axis and $y$ axis, respectively (Fig. 9). By observing the changes in crop loss in scatterplots alongside the TTI value, different crops had various money-loss trends with different typhoon characteristics. From the perspective of different crop losses, these trends can present the sensitivity of crops to different typhoon characteristics.

For example, bitter gourds, papayas, edible corn, bananas, and pomelos, which can be affected by strong winds, were highly correlated with high TTI values in Fig. 9. If the TTI value was larger than zero, then the crop had a positive relationship with the TTI. The larger the TTI value, the larger the crop loss. However, only an extremely high TTI $(>1.8)$ would begin to affect asparagus loss. On the other hand, white bamboo shoots would be affected by strong winds and heavy rainfall, so if TTI $<0$, a smaller TTI would further increase money loss. This type of trend would assume a U shape, with the minimum appearing at TTI $=0$. A third example is calamus, which was almost unaffected by TTI changes.

Furthermore, we could quantify the trend by using the slope of the fitted line from the regression model. According to the two examples in Fig. 10, crops could have different vulnerabilities to wind and rainfall damage. The slope of the regression line can express this characteristic more specifically. The slope for bananas in

TABLE 2. Overall TTIs and the TTIs for the Tainan region from some representative typhoons in the vicinity of Taiwan based on the TTI classification technique proposed in this study.

\begin{tabular}{clcccc}
\hline \hline Typhoon ID & Name & Avg TTI & TTI in Tainan & Cumulative rainfall in Tainan & Avg wind speed in Tainan \\
\hline 200407 & Mindulle & -1.26 & -1.49 & 298.4 & 5.53 \\
200505 & Haitang & 0.94 & 0.93 & 409 & 9.1 \\
200807 & Kalmaegi & -1.22 & -1.08 & 217.5 & 5.11 \\
200908 & Morakot & -0.31 & -1.36 & 739.5 & 10.2 \\
201513 & Soudelor & 1.8 & 1.97 & 242 & 8.415 \\
201614 & Meranti & 0.76 & 1.75 & 139.5 & 7.14 \\
\hline
\end{tabular}


(a) SOUDELOR

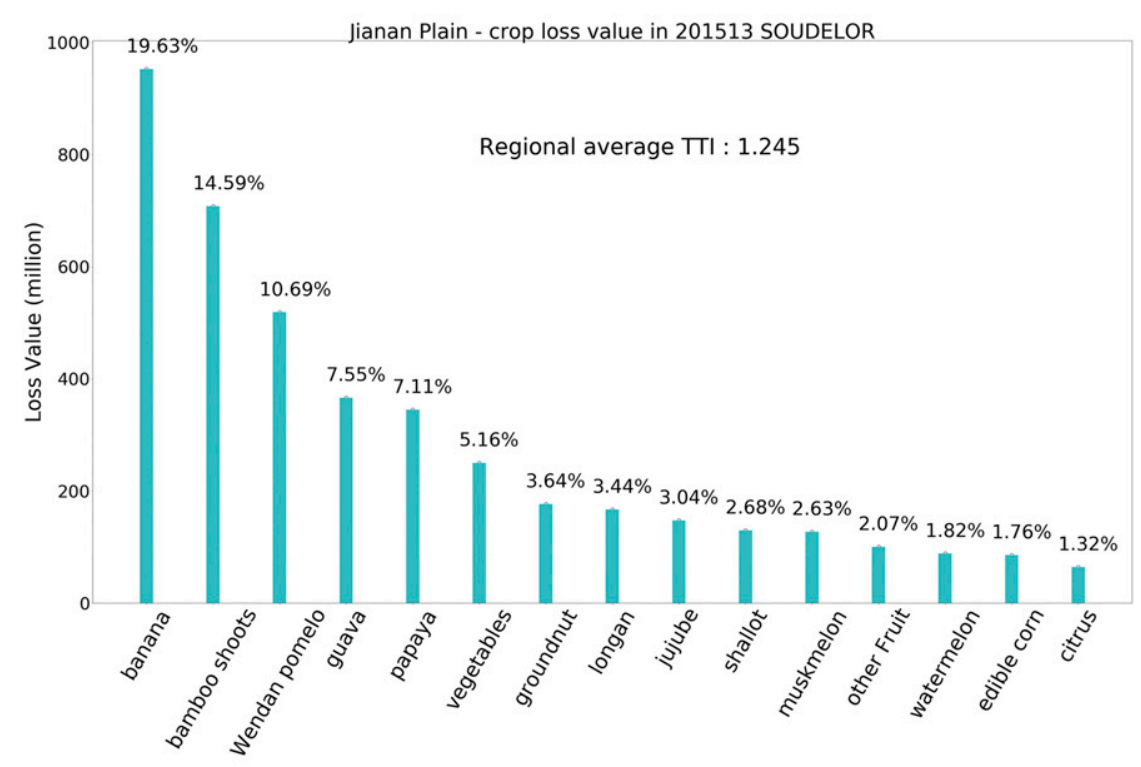

(b) KALMAEGI

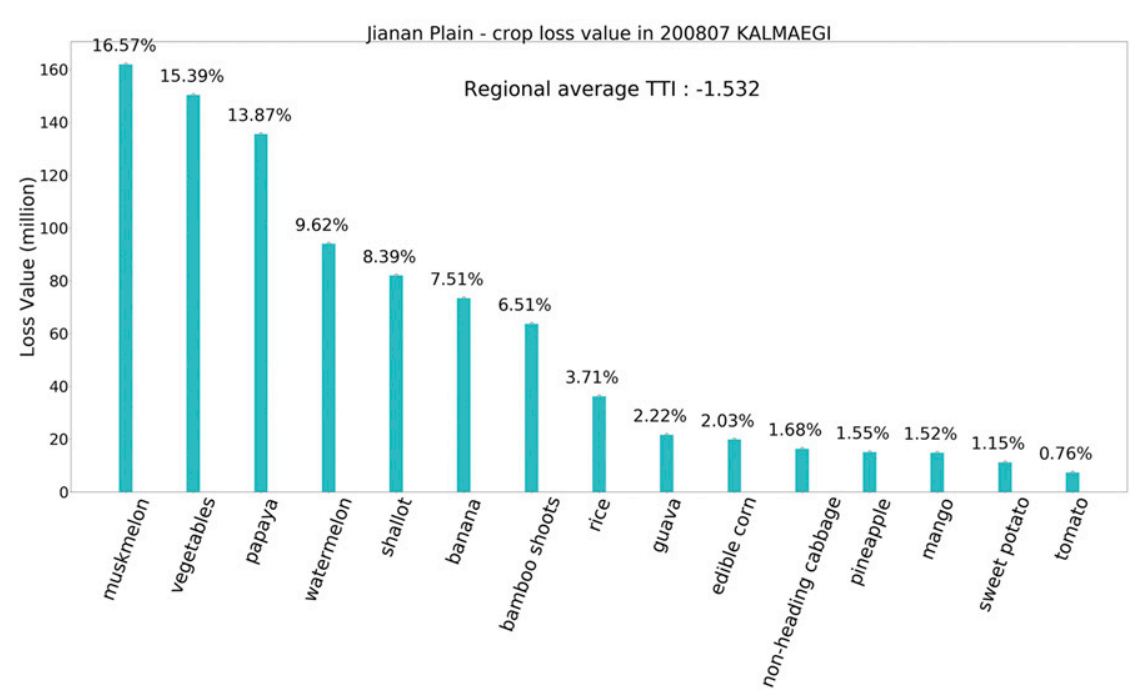

FIG. 8. Bar chart of the Jianan (Chiayi and Tainan area) Plain's crop loss during Typhoons (a) Soudelor and (b) Kalmaegi.

the scatterplot was approximately 0.5 , which is a positive value, so bananas likely experienced greater losses during wind-type typhoons, whose TTIs are positive. On the contrary, polyethylene (PE)-bag mushrooms had a negative slope for the fitted line. Thus, typhoons with lower TTI values (rain-type events) are more likely to cause higher losses for PE-bag mushrooms.

Similarly, we could extend the analysis process for Fig. 9 to determine the slopes of the regression lines of all 82 crops from the raw-data statistics and divide these crops into two categories. The crops with a positive slope could be defined as "wind vulnerable" crops, and those with a negative slope could be defined as "rain vulnerable" crops. With this crop-vulnerability index from slope analysis, we could more specifically describe the vulnerability of crops. Figure 11 shows the slopes of 82 crops. Among them, 11 crops could be classified as rainvulnerable crops, while 71 were wind-vulnerable crops. Moreover, Fig. 11 shows that the number of windvulnerable crops was higher than the number of rainvulnerable crops, so most of the crops were more sensitive to wind damage. Table 3 shows the 20 crops 

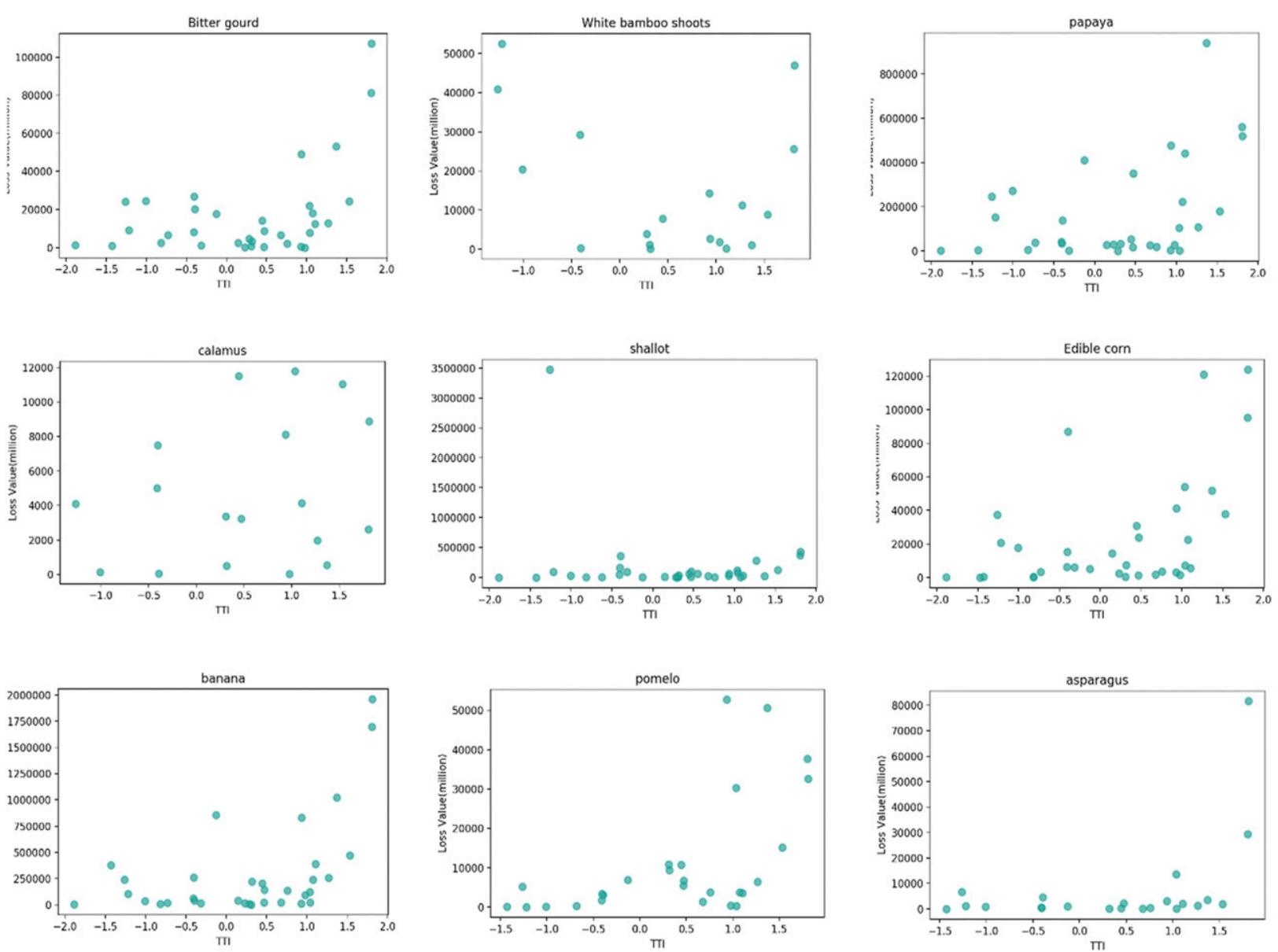

FIG. 9. Scatterplot of each crop, with the TTI value along the $x$ axis and the money loss (millions of New Taiwan Dollars) along the $y$ axis, during every typhoon event from 2003 to 2016.

with the most obvious wind-vulnerable and rain-vulnerable features. For example, jujubes, raw sugar cane, oranges, citrus fruits, kidney beans, pomelos, wax apples, sesames, and guavas were highly wind-vulnerable crops. On the contrary, red beans, tobacco, peaches, white bamboo shoots, PE-bag mushrooms, litchi fruits, shallots, miscellaneous grains, hard corn, and yams were highly rainvulnerable crops.

The research in this section enables us to better understand the loss behavior and trends of different crops from various types of typhoon damage. In addition, applying this slope as a typhoon disaster-vulnerability index for crops can provide valuable information for the risk assessment of crop losses that are caused by typhoon hazards.

\section{Discussion and conclusions}

In this study, the characteristics of typhoons could be described quantitatively in terms of wind and rain features by using the typhoon type index. The TTI is easy and simple to calculate and can elucidate the characteristics of typhoons, including hazards from strong wind and heavy rainfall. In addition, the TTI has multiple applications because several typhoon-induced hazards are related to this index, such as flooding, landslides, mudflows, and urban-building damage. In addition, other typhoon or meteorological characteristics can affect the spatial distribution of the TTI, such as typhoon trajectories, monsoons, and different seasons. At present, meteorological organizations in various countries can already announce quite accurate wind forecasts and quantitative rainfall forecasts before typhoons invasion. One of the advantages of the TTI is that only these two pieces of information are needed and can be quickly applied to disaster prevention in various fields. Therefore, the TTI can also be forecast before a typhoon hits as soon as we have wind forecasts and quantitative rainfall forecasts.

However, for the risk analysis and prevention of typhoon disasters, the proper parameters for the TTI 


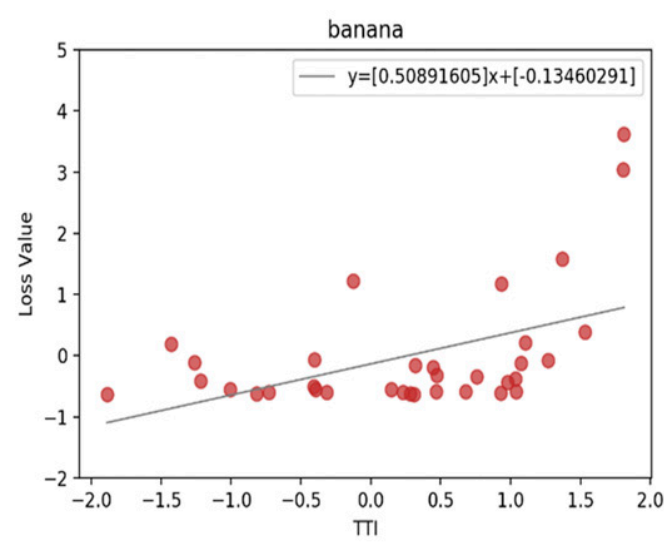

(a)

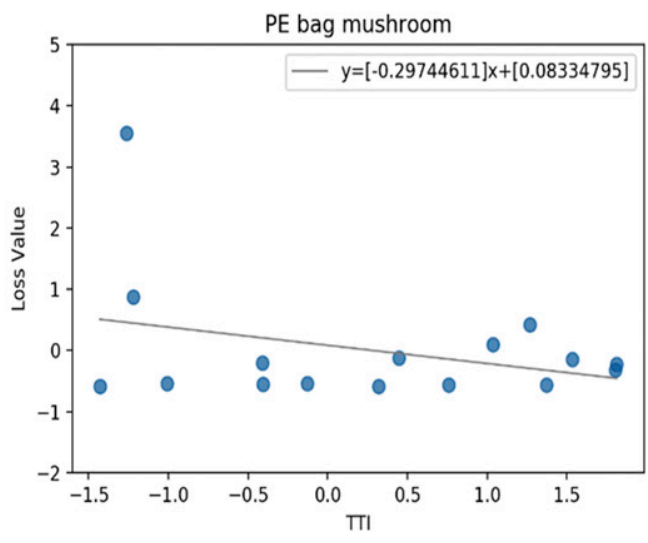

(b)

FIG. 10. Crop-loss regression model from the TTI. The $x$-axis value is the TTI, and the $y$-axis value is the standardized crop's loss value during every typhoon. The slope of the regression line measures the probability of damage for each crop.

regression model are worth discussing. In this classification model, the precipitation parameter that is used is the cumulative rainfall, which can show the total amount of rainfall during the typhoon's warning period but may not precisely describe some special and extreme rainfall events. For example, Typhoon Soudelor (2015) exhibited a short period with heavy rainfall in the Wulai region, causing landslides, flooding, and other devastating

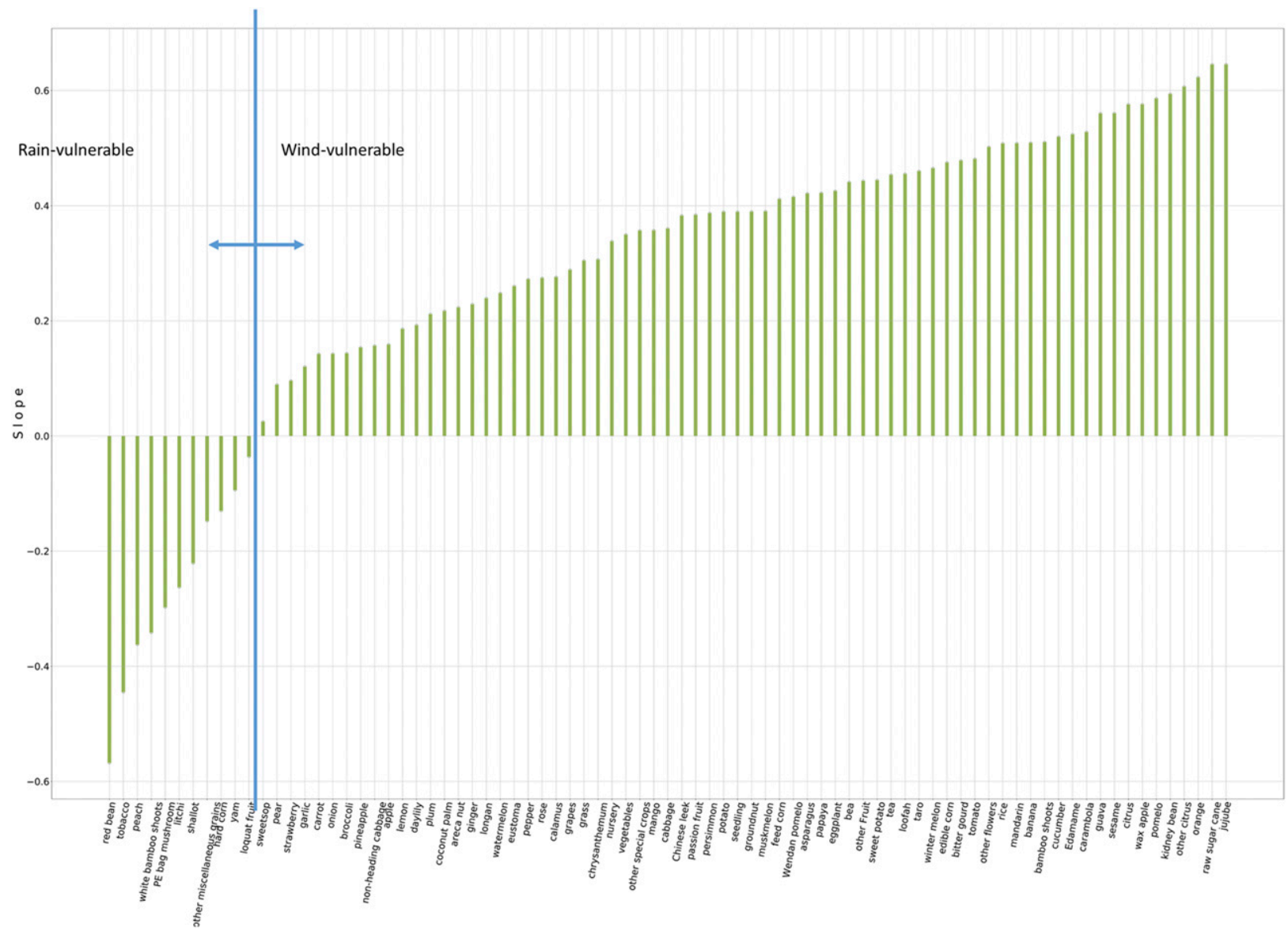

FIG. 11. Slopes of 82 crops. Eleven crops are classified as rain-vulnerable crops, and 71 are wind-vulnerable crops. 
TABLE 3. Twenty most obvious crops with wind-vulnerable (positive slope) and rain-vulnerable (negative slope) features.

\begin{tabular}{lc}
\hline \multicolumn{1}{c}{ Crop } & Slope \\
\hline Guava & 0.56 \\
Sesame & 0.56 \\
Citrus & 0.576 \\
Wax apple & 0.576 \\
Pomelo & 0.586 \\
Kidney bean & 0.594 \\
Other citrus & 0.607 \\
Orange & 0.622 \\
Raw sugar cane & 0.645 \\
Jujube & 0.645 \\
Red bean & -0.568 \\
Tobacco & -0.445 \\
Peach & -0.362 \\
White bamboo shoots & -0.341 \\
PE-bag mushroom & -0.297 \\
Litchi & -0.263 \\
Shallot & -0.221 \\
Other miscellaneous grains & -0.148 \\
Hard corn & -0.13 \\
Yam & -0.094 \\
\hline
\end{tabular}

disasters. However, the TTI of Soudelor in Wulai still tended to be wind type because the current calculation method for the TTI may not show the features of extreme, short-term rainfall. Therefore, we could develop different types of TTIs from these general TTIs for the different characteristics of the study area to further understand some specific events, for example, calculate the TTI based on different wind thresholds or rainfall durations. In addition, we attempted to calculate and classify TTIs by using support vector machines, the generalized additive model, $k$ means, and other nonlinear models. However, the scatterplot results from the perspective of historical typhoon wind and rain characteristics were roughly linear. Therefore, using a traditional linear model has more meaningful interpretation and is easy for other researchers to calculate and apply to other scenarios.

This study developed a new method of typhoon-type classification to explore the characteristics of typhoons in terms of wind and rain features. Many previous methods of typhoon classification did not consider the coupling effects of wind and rain. The most widely known is the method of the Central Weather Bureau and other international meteorological organizations, which can classified typhoons into four degrees according to the maximum average wind speed near the center of the typhoon: tropical depressions, mild typhoons (or tropical storms), moderate typhoons (or "typhoons") and severe typhoons. However, with this classification method, we can only understand the typhoon's wind speed and air pressure and not its rainfall characteristics.
Extreme rainfall from typhoons is also a very important hazard factor that should be considered during typhoonrisk assessment.

In many cases of historical disasters that are caused by typhoons, some serious losses were not caused by strong wind but by heavy rainfall. For example, Typhoon Kalmaegi (2008) was classified as a tropical depression, which does not seem to be a serious typhoon, but the actual circumstance was that Kalmaegi brought strong southwesterly flow and abundant rainfall over two days, causing many disasters and casualties. Therefore, the features of typhoons were further analyzed in this study from the perspective of wind and rain characteristics. Typhoons could be classified into wind-type and raintype events according to the regression model based on cumulative rainfall and $25 \%$ mean wind speed data. Then, we could use the residuals of the statistical regression model as an indicator to further develop the TTI.

Describing a typhoon through the TTI could be more specific in terms of wind and rain characteristics because the TTI represents the degree that a typhoon tends to be a wind-type or rain-type event. After defining the TTI, the spatial distribution of the TTI around Taiwan was developed. The TTI could be obtained from each weather station during the same typhoon, and we realized that the characteristics of typhoons are regional, that is, different regions have different wind and rain characteristics during the same typhoon. This factor is helpful for the risk analysis of regional disasters that are caused by typhoons because wind and rain features are easy to observe on spatial distribution maps.

In the last section of this study, we analyzed the relationship between agricultural losses and typhoon characteristics. The crop-loss data from the Council of Agriculture revealed that some crops are particularly sensitive to certain types of typhoons. Wind-type typhoons tend to damage crops whose fruits or branches are easily blown off, such as bananas, pomelos, and papayas. Meanwhile, rain-type typhoons more easily damage crops that are vulnerable to soaking in water under heavy rainfall, such as melon crops and leafy vegetables. The statistical analysis showed that the TTI can be an effective indicator to explain any considerable correlations between the type of damaged crop and the type of typhoon. Moreover, this analysis is more accurate from a regional perspective, that is, regional TTI values can better explain agricultural damage.

To better understand the loss behavior and trends of crops under different types of typhoon damage, this study applied the slope of a linear model as a typhoon disaster-vulnerability index for crops. With this index, crops could be divided into two categories according to their vulnerability to wind and rainfall damage. 
This index is a specific approach to describe a crop's sensitivity. The TTI could become an important forecasting factor before future typhoons as a reference indicator for disaster prevention in various fields. This study could serve as a reference for risk analysis under different typhoon types and could be very helpful for the risk prevention of typhoon disasters and agricultural damage.

Acknowledgments. We are grateful to the funding support from the Ministry of Science and Technology (MOST) in Taiwan, projects MOST 108-2636-E-008-004 (Young Scholar Fellowship Program), MOST 107-2119M-008-006, MOST 107-2119-M-008-019, and MOST 106-2621-M-002-002. We also thank the National Science and Technology Center for Disaster Reduction (NCDR) and credit the original data from the Central Weather Bureau (CWB), Taiwan Typhoon and Flood Research Institute (TTFRI), and Council of Agriculture, Executive Yuan. We acknowledge the Python programming language and its modules as a powerful tool in our data analysis.

\section{REFERENCES}

Blennow, K., and O. Sallnäs, 2004: WINDA-A system of models for assessing the probability of wind damage to forest stands within a landscape. Ecol. Modell., 175, 87-99, https://doi.org/ 10.1016/j.ecolmodel.2003.10.009.

Chang, C. C., and C. J. Lin, 2011: LIBSVM: A library for support vector machines. ACM Trans. Intell. Syst. Technol., 2, 1-27, https://doi.org/10.1145/1961189.1961199.

Chen, C.-S., Y.-L. Lin, H.-T. Zeng, C.-Y. Chen, and C.-L. Liu, 2013: Orographic effects on heavy rainfall events over northeastern Taiwan during the northeasterly monsoon season. Atmos. Res., 122, 310-335, https://doi.org/10.1016/j.atmosres.2012.10.008.

Chen, W. K., G. Sui, and D. Tang, 2011: A fuzzy intelligent decision support system for typhoon disaster management. 2011 IEEE Int. Conf. on Fuzzy Systems (FUZZ-IEEE 2011), Taipei, Taiwan, IEEE, 364-367, https://doi.org/10.1109/ FUZZY.2011.6007575

Chien, F.-C., and H.-C. Kuo, 2011: On the extreme rainfall of Typhoon Morakot (2009). J. Geophys. Res., 116, D05104, https://doi.org/10.1029/2010JD015092.

_ , Y.-C. Liu, and C.-S. Lee, 2008: Heavy rainfall and southwesterly flow after the leaving of Typhoon Mindulle (2004) from Taiwan. J. Meteor. Soc., 86, 17-41, https://doi.org/ 10.2151/jmsj.2012-510.

Crane, J., C. Balerdi, R. Campbell, C. Campbell, and S. Goldweber, 1994: Managing fruit orchards to minimize hurricane damage. Horttechnology, 4, 21-27, https://doi.org/10.21273/ HORTTECH.4.1.21.

Dutta, D., and S. Herath, 2001: GIS based flood loss estimation modeling in Japan. Proc. First Workshop for Comparative Study on Urban Earthquake Disaster Management, Kobe, Japan, 151-161.

$-\frac{1}{-}$, and K. Musiake, 2003: A mathematical model for flood loss estimation. J. Hydrol., 277, 24-49, https://doi.org/10.1016/ S0022-1694(03)00084-2.
Dvorak, V. F., 1984: Tropical cyclone intensity analysis using satellite data. NOAA Tech. Rep. NESDIS 11, 47 pp., http:// satepsanone.nesdis.noaa.gov/pub/Publications/Tropical/ Dvorak_1984.pdf.

Ekström, M., H. J. Fowler, C. G. Kilsby, and P. D. Jones, 2005: New estimates of future changes in extreme rainfall across the UK using regional climate model integrations. 2. Future estimates and use in impact studies. J. Hydrol., 300, 234-251, https:// doi.org/10.1016/j.jhydrol.2004.06.019.

Forte, F., R. O. Strobl, and L. Pennetta, 2006: A methodology using GIS, aerial photos and remote sensing for loss estimation and flood vulnerability analysis in the Supersano-RuffanoNociglia Graben, southern Italy. Environ. Geol., 50, 581-594, https://doi.org/10.1007/s00254-006-0234-0.

French, M. N., W. F. Krajewski, and R. R. Cuykendall, 1992: Rainfall forecasting in space and time using a neural network. J. Hydrol., 137 (1-4), 1-31, https://doi.org/10.1016/ 0022-1694(92)90046-X.

Gardiner, B., K. Byrne, S. Hale, K. Kamimura, S. J. Mitchell, H. Peltola, and J.-C. Ruel, 2008: A review of mechanistic modelling of wind damage risk to forests. Forestry, 81, 447463, https://doi.org/10.1093/forestry/cpn022.

_ , P. Berry, and B. Moulia, 2016: Wind impacts on plant growth, mechanics and damage. Plant Sci., 245, 94-118, https://doi.org/ 10.1016/j.plantsci.2016.01.006.

Ge, X. Y., T. Li, S. J. Zhang, and M. Peng, 2010: What causes the extremely heavy rainfall in Taiwan during Typhoon Morakot (2009)? Atmos. Sci. Lett., 11, 46-50, https://doi.org/10.1002/ asl.255.

Goswami, B. N., V. Venugopal, D. Sengupta, M. S. Madhusoodanan, and P. K. Xavier, 2006: Increasing trend of extreme rain events over India in a warming environment. Science, 314, 1442-1445, https://doi.org/10.1126/science.1132027.

Gresham, C. A., T. M. Williams, and D. J. Lipscomb, 1991: Hurricane Hugo wind damage to southeastern U.S. coastal forest tree species. Biotropica, 23, 420-426, https://doi.org/ $10.2307 / 2388261$

Hsiao, L. F., and Coauthors, 2013: Ensemble forecasting of typhoon rainfall and floods over a mountainous watershed in Taiwan. J. Hydrol., 506, 55-68, https://doi.org/10.1016/ j.jhydrol.2013.08.046.

Huang, J.-C., C.-K. Yu, J.-Y. Lee, L.-W. Cheng, T.-Y. Lee, and S.-J. Kao, 2012: Linking typhoon tracks and spatial rainfall patterns for improving flood lead time predictions over a mesoscale mountainous watershed. Water Resour. Res., 48 , W09540, https://doi.org/10.1029/2011WR011508.

Huang W. C., M. C. Weng, and R. K. Chen, 2014: Levee failure mechanisms during the extreme rainfall event: A case study in southern Taiwan. Nat. Hazards, 70, 1287-1307, https://doi.org/ 10.1007/s11069-013-0874-9.

IPCC, 2007: Climate Change 2007: The Physical Science Basis. Cambridge University Press, 996 pp.

Keerthi, S. S., and C. J. Lin, 2003: Asymptotic behaviors of support vector machines with Gaussian kernel. Neural Comput., 15, 1667-1689, https://doi.org/10.1162/089976603321891855.

Kuligowski, R. J., and A. P. Barros, 1998: Localized precipitation forecasts from a numerical weather prediction model using artificial neural networks. Wea. Forecasting, 13, 1194-1204, https://doi.org/10.1175/1520-0434(1998)013<1194:LPFFAN > 2.0.CO;2

Lai, L.-H., and P.-H. Wu, 2010: Risk analysis of rice losses caused by typhoon for Taiwan. Contemp. Manage. Res., 6, 141, https:// doi.org/10.7903/cmr.1158. 
Lee, C. S., L. R. Huang, H. S. Shen, and S. T. Wang, 2006: A climatology model for forecasting typhoon rainfall in Taiwan. Nat. Hazards, 37, 87-105, https://doi.org/10.1007/s11069-005-4658-8.

Lin, G. F., and L. H. Chen, 2005: Application of an artificial neural network to typhoon rainfall forecasting. Hydrol. Processes, 19 , 1825-1837, https://doi.org/10.1002/hyp.5638.

— , and M. C. Wu, 2009: A hybrid neural network model for typhoon-rainfall forecasting. J. Hydrol., 375, 450-458, https:// doi.org/10.1016/j.jhydrol.2009.06.047.

Lin, Y.-C., T.-J. Chang, M.-M. Lu, and H.-L. Yu, 2015: A spacetime typhoon trajectories analysis in the vicinity of Taiwan. Stochastic Environ. Res. Risk Assess., 29, 1857-1866, https:// doi.org/10.1007/s00477-014-1001-5.

Lin, Y. L., D. B. Ensley, S. Chiao, and C. Y. Huang, 2002: Orographic influences on rainfall and track deflection associated with the passage of a tropical cyclone. Mon. Wea. Rev., 130, 2929-2950, https://doi.org/10.1175/1520-0493(2002)130<2929: OIORAT $>2.0 . \mathrm{CO} ; 2$.

Lonfat, M., R. Rogers, T. Marchok, and F. D. Marks, 2007: A parametric model for predicting hurricane rainfall. Mon. Wea. Rev., 135, 3086-3097, https://doi.org/10.1175/MWR3433.1.

Messner, F., and V. Meyer, 2006: Flood damage, vulnerability and risk perception-Challenges for flood damage research. Flood Risk Management: Hazards, Vulnerability and Mitigation Measures, NATO Science Series, Vol. 67, J. Schanze et al., Eds., Springer, 149-167.

Mohan, P., 2017: Impact of hurricanes on agriculture: Evidence from the Caribbean. Nat. Hazards Rev., 18, 04016012, https:// doi.org/10.1061/(ASCE)NH.1527-6996.0000235.

Pan, T. Y., Y. T. Yang, H. C. Kuo, Y. C. Tan, J. S. Lai, T. J. Chang, C. S. Lee, and K. H. Hsu, 2011: Improvement of statistical typhoon rainfall forecasting with ANN-based southwest monsoon enhancement. Terr. Atmos. Ocean. Sci., 22, 633645, https://doi.org/10.3319/TAO.2011.07.04.01(TM).

Scawthorn, C., and Coauthors, 2006: HAZUS-MH flood loss estimation methodology. II. Damage and loss assessment. Nat. Hazards Rev., 7, 72-81, https://doi.org/10.1061/(ASCE)15276988(2006)7:2(72).
Shanmugasundaram, J., and G. Reardon, 1995: Strong wind damage due to Hurricane Andrew and its implications. J. Struct. Eng., 22, 49-54.

Tu, J. Y., and C. Chou, 2013: Changes in precipitation frequency and intensity in the vicinity of Taiwan: Typhoon versus nontyphoon events. Environ. Res. Lett., 8, 014023, https://doi.org/ 10.1088/1748-9326/8/1/014023.

Vapnik, V. N., 1998: Statistical Learning Theory. Wiley, 768 pp.

Wang, Y., J. Zhang, E. Guo, and Z. Sun, 2015: Fuzzy comprehensive evaluation-based disaster risk assessment of desertification in Horqin Sand Land, China. Int. J. Environ. Res. Public Health, 12, 1703-1725, https://doi.org/10.3390/ ijerph120201703.

Wu, C. C., T. H. Yen, Y. H. Kuo, and W. Wang, 2002: Rainfall simulation associated with typhoon herb (1996) near Taiwan. Part I: The topographic effect. Wea. Forecasting, 17, 1001-1015, https://doi.org/10.1175/1520-0434(2003)017<1001: RSAWTH $>2.0 . \mathrm{CO} ; 2$.

Yang, C. R., and C. T. Tsai, 2000: Development of a GIS-based flood information system for floodplain modeling and damage calculation. J. Amer. Water Resour. Assoc., 36, 567-577, https://doi.org/10.1111/j.1752-1688.2000.tb04287.x.

Yeh, T. C., and R. L. Elsberry, 1993a: Interaction of typhoons with the Taiwan orography. Part I: Upstream track deflections. Mon. Wea. Rev., 121, 3193-3212, https://doi.org/10.1175/15200493(1993)121<3193:IOTWTT>2.0.CO;2.

_ orography. Part II: Continuous and discontinuous tracks across the island. Mon. Wea. Rev., 121, 3213-3233, https://doi.org/ 10.1175/1520-0493(1993)121<3213:IOTWTT>2.0.CO;2.

Yilmaz, A. G., I. Hossain, and B. J. C. Perera, 2014: Effect of climate change and variability on extreme rainfall intensityfrequency-duration relationships: A case study of Melbourne. Hydrol. Earth Syst. Sci., 18, 4065-4076, https://doi.org/10.5194/ hess-18-4065-2014.

Zhou, R., and A. H. S. Chan, 2016: Using a fuzzy comprehensive evaluation method to determine product usability: A test case. Work, 56, 21-29, https://doi.org/10.3233/WOR-162473. 